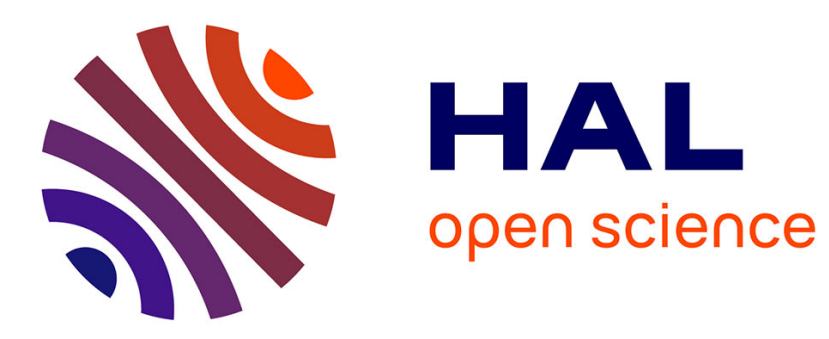

\title{
Passive and impulsive synchronization of a new four-dimensional chaotic system
}

Hamid Hamiche, Karim Kemih, Malek Ghanes, Gang Zheng, Said Djennoune

\section{To cite this version:}

Hamid Hamiche, Karim Kemih, Malek Ghanes, Gang Zheng, Said Djennoune. Passive and impulsive synchronization of a new four-dimensional chaotic system. Nonlinear Analysis: Theory, Methods and Applications, 2011, 74 (4). hal-00640513v1

\section{HAL Id: hal-00640513 https://hal.inria.fr/hal-00640513v1}

Submitted on 5 Jan 2012 (v1), last revised 20 Jul 2012 (v2)

HAL is a multi-disciplinary open access archive for the deposit and dissemination of scientific research documents, whether they are published or not. The documents may come from teaching and research institutions in France or abroad, or from public or private research centers.
L'archive ouverte pluridisciplinaire HAL, est destinée au dépôt et à la diffusion de documents scientifiques de niveau recherche, publiés ou non, émanant des établissements d'enseignement et de recherche français ou étrangers, des laboratoires publics ou privés. 


\title{
Passive and impulsive synchronization of a new four-dimensional chaotic system
}

\author{
Hamid Hamiche $^{\mathrm{a}}$, Karim Kemih ${ }^{\mathrm{b}}$, Malek Ghanes ${ }^{\mathrm{c}}$, Gang Zhang ${ }^{\mathrm{d}}$, Saïd \\ Djennoune $^{\mathrm{a}}$ \\ ${ }^{a}$ Laboratoire de Conception et Conduite des Systèmes de Production, UMMTO, BP 17 \\ RP, 15000, Tizi-Ouzou, Algérie. \\ ${ }^{b}$ Equipe Analyse et Commande des Systèmes, Laboratoire LAMEL, Université de Jijel, \\ Algérie. \\ ${ }^{c}$ Equipe Commande des Systèmes (ECS), ENSEA, 6 Avenue du Ponceau, 95014 \\ Cergy-Pontoise Cedex, France. \\ ${ }^{d}$ INRIA Lille - Nord Europe, France.
}

\begin{abstract}
This paper studies the synchronization problem of a new chaotic four-Dimensional System presented by Qi et al. Two different methods, passive control method and impulsive control method are used to control synchronization of the fourdimensional chaotic system. Numerical simulations show the effectiveness of the two different methods.

Keywords: Qi Four-dimensional chaotic system, Chaotic synchronization, Passive control. Impulsive control.
\end{abstract}

\section{Introduction}

In 1963, Lorenz found the first a chaotic attractor in a simple threedimensional autonomous system (Sparrow, 1982). Later, an even simpler three-dimensional chaotic system, which has only one cross-product term, was constructed by Rössler (Rössler, 1976). In 1999, Chen and Ueta presented another well-known three-dimensional chaotic system (Chen et al., 1999), referred to as Chen system that has been proved to be dual and topologically nonequivalent to Lorenz system. Whereafter, Lü system (Lü et al. , 2002), a critical system between Lorenz and Chen system, was constructed in 2002, followed by the Lorenz system family (Lü et al., 2003) as a connection of Lorenz, Chen and Lü systems; so far, there are many researchers who 
studied the chaos theory (Wu et al. , 2007).

During the last decades dynamic chaos theory has been deeply studied and applied to many fields extensively, such as secure communications, optical system, biology and so forth (Sun, 2004).

Recently, (Qi et al. , 2005) constructed a new 4D autonomous chaotic system, which has cubic cross-product nonlinearity in each equation. This system can generate complex dynamics within wide parameters ranges, including chaos, Hopf bifurcation, perioddoubling bifurcation, periodic orbit, sink and source, and so on (Qi et al. , 2006).

The problem of chaos synchronization is directly related to the observer problem in control theory. In general, the designed controller with the state variable of the master will make the trajectories of the state variables of the slave system to track the trajectories of the state variables of the driver system (Vincent et al. , 2008).

Until now, many different techniques and methods have been proposed to achieve chaos synchronization, such as OGY method (Lai et al. , 1993), linear feed-back method (Han et al. , 2004), adaptive synchronization method (Liao et al. , 1998), backstepping nonlinear control method (Tan et al. , 2003), sliding mode control method (Shimizu et al. , 2005), active control (Vincent et al. , 2008) and projective synchronization method (liu et al. , 2007).

In the present paper, the passive control and impulsive control methods are applied to synchronize two identical new chaotic four-Dimensional System presented by Qi et al. Numerical simulations show the effectiveness of the two different methods.

\section{System description}

We consider the new $4 D$ chaotic system to be synchronized described by (Qi et al. , 2005):

$$
\left\{\begin{array}{l}
\dot{x_{1}}=a\left(x_{2}-x_{1}\right)+x_{2} x_{3} x_{4} \\
\dot{x_{2}}=b\left(x_{1}+x_{2}\right)-x_{1} x_{3} x_{4} \\
\dot{x_{3}}=-c x_{3}+x_{1} x_{2} x_{4} \\
\dot{x_{4}}=-d x_{4}+x_{1} x_{2} x_{3}
\end{array}\right.
$$

where $c=c_{1}+c_{2} \sin (t)$, and $a, b, c_{1}, c_{2}, d$ are all positive real constant parameters. The dynamics of this system has been extensively investigated by Qi et al. For a fixed subset of the system parameters with autonomous case 
$c_{2}=0$ and non-autonomous case $c_{2} \neq 0$. The dependence of the bifurcation diagrams and the Lyapunov exponent that were a function of the parameter $d$ were presented. In particular, the $4 D$ system exhibits chaotic behavior for the following parameters:

Case I: autonomous case

$a=35, b=10, c_{1}=1, c_{2}=0, d=10$.

Case II: non-autonomous case

$a=30, b=10, c_{1}=95, c_{2}=10, d=10$.

Figures 1 and 2 shows the chaotic attractor of the system for case I and case II.
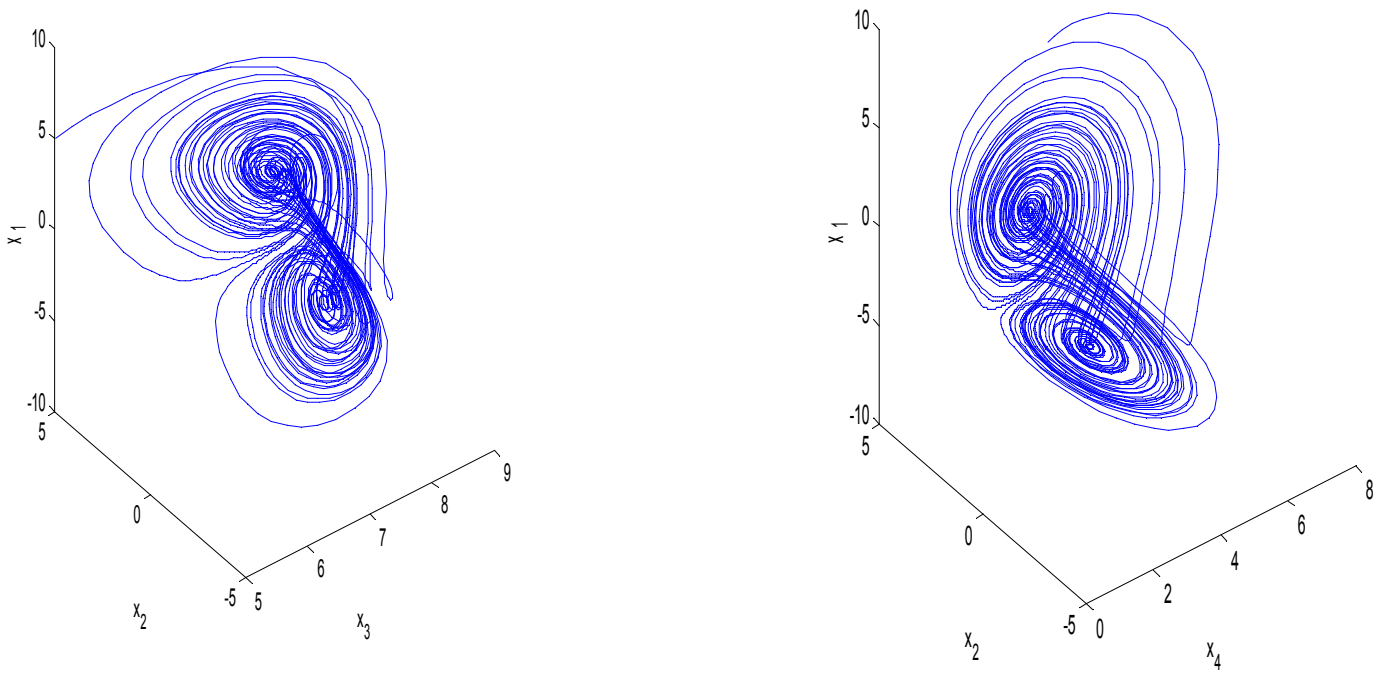

Figure 1: Views of the chaotic attractor of the system: case I

\section{Synchronization of the $4 \mathrm{D}$ chaotic system}

\subsection{Passive control method}

Some preliminaries of passivity theory used in this paper will be shortly reviewed for the consistency of the presentation. Passivity is applied to nonlinear systems which are modelled by ordinary differential equations with 

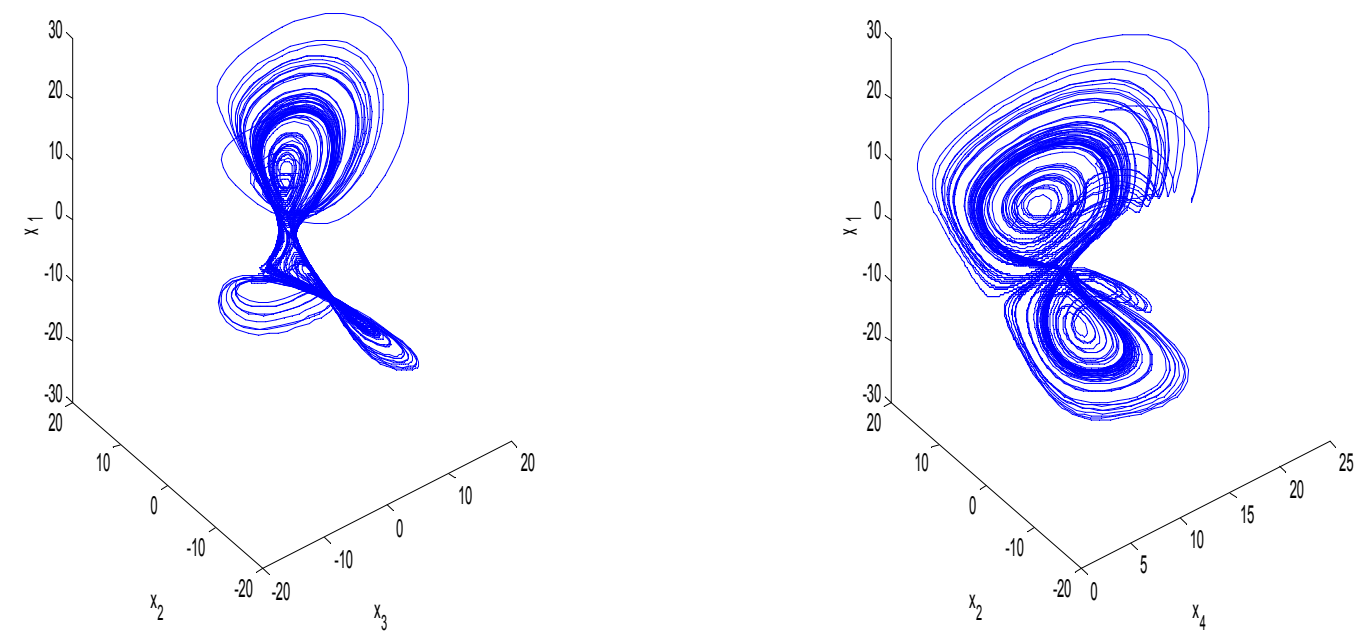

Figure 2: Views of the chaotic attractor of the system: case II

input vector $u(t)$ and output vector $y(t)(\mathrm{Yu}, 1999)$ and (Kemih et al. , 2007):

$$
\left\{\begin{array}{l}
\dot{x}(t)=f(x(t), u(t)) \\
y(t)=h(x(t))
\end{array}\right.
$$

The system (1) is dissipative with the supply rate $W(u(t), y(t))$ if it is not able to generate power by itself, that is the energy stored in the system is less than or equal to the supplied power:

$$
V(x(t)) \geq 0 \text { and } V(x(T))-V(x(0)) \leq \int_{0}^{T} W(u(t), y(t)) d t
$$

Furthermore, the storage function $V(x(t))$ must satisfy the requirements for a Lyapunov function. If there exist a positive semi definite Lyapunov function, such that:

$$
\begin{array}{r}
\int u^{T}(\tau) y(\tau) d \tau \geq \int\left[\frac{\partial V(x(\tau))}{\partial x(\tau)} f(x \tau), u(\tau)\right)+e u^{T} \\
\left.+\delta y^{T}(\tau) y(\tau)+\rho \Phi(x(\tau))\right] d \tau
\end{array}
$$


The system (1) is passive. A passive system implies that any increase in storage energy is due solely to an external power supply.

Then the equilibrium point of the system:

$$
\dot{x}=f(t, x(t), 0)
$$

is asymptotically stable in either of the two cases:

- $\rho>0$

- $e+\delta>0$ and the system is zeros-state observation.

The system (1) can be represented as the normal form:

$$
\left\{\begin{array}{l}
\dot{x}=f(z)+g(z, y) y \\
\dot{y}=l(z, y)+k(z, y) u
\end{array}\right.
$$

The nonlinear system (5) may be rendered bay a state feedback of the form (Yu, 1999):

$$
u=\gamma+\beta(x) v
$$

The dynamical system is described as:

$$
\left\{\begin{array}{l}
\dot{x_{1}}=a\left(x_{2}-x_{1}\right)+x_{2} x_{3} x_{4} \\
\dot{x_{2}}=b\left(x_{1}+x_{2}\right)-x_{1} x_{3} x_{4} \\
\dot{x_{3}}=-c x_{3}+x_{1} x_{2} x_{4} \\
\dot{x_{4}}=-d x_{4}+x_{1} x_{2} x_{3}
\end{array}\right.
$$

While the response system can be described as:

$$
\left\{\begin{array}{l}
\dot{y_{1}}=a\left(y_{2}-y_{1}\right)+y_{2} y_{3} y_{4} \\
\dot{y}_{2}=b\left(y_{1}+y_{2}\right)-y_{1} y_{3} y_{4}+u \\
\dot{y}_{3}=-c y_{3}+y_{1} y_{2} y_{4} \\
\dot{y_{4}}=-d y_{4}+y_{1} y_{2} y_{3}
\end{array}\right.
$$

Now define the error states are: $e_{1}=y_{1}-x_{1}, e_{2}=y_{2}-x_{2}, e_{3}=y_{3}-x_{3}$ and $e_{4}=y_{4}-x_{4}$, so the dynamics of the error system is determined as following:

$$
\left\{\begin{array}{l}
\dot{e_{1}}=a\left(e_{2}-e_{1}\right)+y_{2} y_{3} y_{4}-x_{2} x_{3} x_{4} \\
\dot{e_{2}}=b\left(e_{1}+e_{2}\right)-y_{1} y_{3} y_{4}+x_{1} x_{3} x_{4}+u \\
\dot{e_{3}}=-c e_{3}+y_{1} y_{2} y_{4}-x_{1} x_{2} x_{4} \\
\dot{y_{4}}=-d e_{4}+y_{1} y_{2} y_{3}-x_{1} x_{2} x_{3}
\end{array}\right.
$$


Let system (9) is already in the normal form of (5), where: $z_{1}=e_{1}, z_{2}=e_{3}$, $z_{3}=e_{4}, y=e_{2}, z=\left[z_{1}, z_{2}, z_{3}\right]^{T}$,

$$
\begin{gathered}
f(z)=\left[-a z_{1}+y_{2} y_{3} y_{4}-x_{2} x_{3} x_{4},-c z_{2}+y_{1} y_{2} y_{4}-x_{1} x_{2} x_{4},-d z_{3}+y_{1} y_{2} y_{3}-x_{1} x_{2} x_{3}\right]^{T}, \\
g(z, y)=[a, 0,0]^{T}, l(z, y)=b z_{1}+b y-y_{1} y_{3} y_{4}+x_{1} x_{3} x_{4}, \quad k(z, y)=1
\end{gathered}
$$

Our object is to design a smooth control (6) for the $4 D$ chaotic system to make the closed-loop system passive. Choose a storage function candidate:

$$
V(z, y)=W(z)+\frac{1}{2} y^{2}
$$

where $W(z)$ is Lyapunov function with $W(0)=0$,

$$
W(z)=\frac{1}{2}\left(z_{1}^{2}+z_{2}^{2}+z_{3}^{2}\right)
$$

The zero dynamics of the system (9) describes those internal dynamics which are consistent with external constraint $y=0$, i.e.,

$$
\dot{z}=f(z)
$$

Consider (13):

$$
\begin{gathered}
\frac{d}{d t} W(z)=\left[\begin{array}{lll}
z_{1} & z_{2} & z_{3}
\end{array}\right] f(z) \\
=\left(-a z_{1}+y_{2} y_{3} y_{4}-x_{2} x_{3} x_{4}\right) z_{1}+\left(-c z_{2}+y_{1} y_{2} y_{4}-x_{1} x_{2} x_{4}\right) z_{2} \\
+\left(-d z_{3}+y_{1} y_{2} y_{3}-x_{1} x_{2} x_{3}\right) z_{3} \leq 0
\end{gathered}
$$

The zero dynamics of error synchronization system is Lyapunov stable. The derivative of $V(z, y)$ along the trajectory of the $4 D$ chaotic system (9) is:

$$
\begin{aligned}
\frac{d}{d t} V(z, y) & =\frac{\partial}{\partial z} W(z) \dot{z}+y \dot{y} \\
& =\frac{\partial}{\partial z} W(z) f(z)+\frac{\partial}{\partial z} W(z) g(z, y) y+l(z, y) y+k(z, y) u y
\end{aligned}
$$

The error system is minimum phase:

$$
\frac{d}{d t} W(z) f(z) \leq 0
$$


Equation (15) becomes:

$$
\frac{d}{d t} V(z, y) \leq \frac{\partial}{\partial z} W(z) g(z, y) y+(l(z, y)+k(z, y) u) y
$$

If we select the feedback control (6) of the following form and consider (9):

$$
\begin{aligned}
u & =k^{-1}(z, y)\left[-l^{T}(z, y)-\frac{\partial W}{\partial z} g(z, y)-\gamma y+v\right] \\
& =-(a+b) z_{1}-(b+\gamma) y+y_{1} y_{2} y_{3}-x_{1} x_{2} x_{3}+v
\end{aligned}
$$

where $\gamma$ is positive constant and $v$ is an external signal which is connected with the reference input. The above inequality can be rewritten as:

$$
\frac{d}{d t} V(z, y) \leq-\gamma y^{2}+v y
$$

Then integrating both side of (19)

$$
\begin{gathered}
V(z, y)-V\left(z_{0}, y_{0}\right) \leq \int_{0}^{t}-\gamma y(\tau)^{2} d \tau+\int_{0}^{t} v(\tau) y(\tau) d \tau \\
V(z, y) \geq 0 \text { and } \rho=V\left(z_{0}, y_{0}\right) \\
\int_{0}^{t} v(\tau) y(\tau) d \tau+\rho \geq V(z, y)+\int_{0}^{t}-\gamma y(\tau)^{2} d \tau \geq \int_{0}^{t}-\gamma y(\tau)^{2} d \tau
\end{gathered}
$$

It satisfies the passive definition (3). The $4 D$ chaotic system (9) is rendered to be output strict passive (OSP) under the feedback control.

\subsection{Impulsive control method}

We decompose the linear and nonlinear parts of the four-dimensional system in Eq.(9) and rewrite it as :

$$
\dot{e}=A e+\Phi(e)
$$

where:

$$
e=\left(e_{1}, e_{2}, e_{3}\right)^{T}, A=\left[\begin{array}{cccc}
-a & a & 0 & 0 \\
b & b & 0 & 0 \\
0 & 0 & -c & 0 \\
0 & 0 & 0 & -d
\end{array}\right]
$$


and

$$
\Phi(x)=\left[\begin{array}{c}
y_{2} y_{3} y_{4}-x_{2} x_{3} x_{4} \\
-y_{1} y_{3} y_{4}+x_{1} x_{3} x_{4} \\
y_{1} y_{2} y_{4}-x_{1} x_{2} x_{4} \\
y_{1} y_{2} y_{3}-x_{1} x_{2} x_{3}
\end{array}\right]
$$

Then, the impulsive control of the critical system is given by (Zhang et al. , 2007):

$$
\left\{\begin{array}{l}
\dot{E}=A E+\Phi(e), t \neq t_{i} \\
\Delta E=B E, \quad t=t_{i}, i=1,2, \ldots \\
e\left(t_{0}^{+}\right)=e_{0}
\end{array}\right.
$$

Where $t_{i}$ denotes the instant when impulsive control occurs. For convenience, define the following notation:

$$
\lambda_{2}(A)=\frac{1}{2} \lambda_{\max }\left(A+A^{T}\right), \beta_{i}=\lambda_{\max }\left[\left(I+B_{i}\right)^{T}\left(I+B_{i}\right)\right]
$$

Where $I$ is the $n \times n$ identity matrices, and $\lambda_{\max }(A)$ is the maximal eigenvalue of matrices $A$.

Theorem 1. 1. If $2 \lambda_{2}(A)=\lambda<0$ ( $\lambda$ is a constant) and there exists a constant $0 \leq \alpha<-\lambda$, such that

$$
\ln \beta_{i}-\alpha\left(t_{i}-t_{i-1}\right) \leq 0, k=1,2, \ldots
$$

Then the trivial solution of system (9) is globally exponentially stable.

2. If $2 \lambda_{2}(A)=\lambda \geq 0$ ( $\lambda$ is a constant) and there exists a constant $\alpha \geq 1$, such that

$$
\ln \left(\alpha \beta_{i}\right)+\lambda\left(t_{i+1}-t_{i}\right) \leq 0, k=1,2, \ldots
$$

Then $\alpha=1$ implies that the trivial solution of system (9) is stable and $\alpha>1$ implies that the trivial solution of system (9) is globally asymptotically stable.

Proof 1. Let the Lyapunov function be in the form of: $v(x)=x^{T} x$ The time derivative of $V(x)$ along with the solution of Eq.(9) is :

$$
\begin{aligned}
\dot{V}(x) & =\dot{x}^{T} x+x^{T} \dot{x}=(A x+\Phi)^{T} x+x^{T}(A e+\Phi) \\
& =e^{T}\left(A^{T}+A\right) e+\Phi^{T} e+e^{T} \Phi \\
& \leq 2 \lambda_{2}(A) v(e(t)), t \in\left(t_{i-1}, t_{i}\right], i=1,2, \ldots
\end{aligned}
$$


Which implies that:

$$
V(e(t)) \leq V\left(e\left(t_{i-1}^{+}\right)\right) \exp \left(2 \lambda_{2}(A)\left(t-t_{i-1}\right)\right), t \in\left(t_{i-1}, t_{i}\right], i=1,2, \ldots
$$

On the other hand, it follows from system (10) that

$$
\begin{aligned}
& V\left(t_{i}^{+}\right)=\left(\left[I+B_{i}\right) e\left(t_{i}\right)\right]^{T}\left(I+B_{i}\right) e\left(t_{i}\right) \\
& \leq \beta_{i} V\left(e\left(t_{i}\right)\right), i=1,2, \ldots
\end{aligned}
$$

The following results come from (14) and (15). For $t \in\left(t_{0}, t_{1}\right]$

$$
V(e(t)) \leq V\left(e\left(t_{0}^{+}\right)\right) \exp \left(2 \lambda_{2}(A)\left(t-t_{0}\right)\right)
$$

which leads to

$$
\begin{aligned}
V\left(e\left(t_{1}\right)\right) & \leq V\left(e\left(t_{0}^{+}\right)\right) \exp \left(2 \lambda_{2}(A)\left(t_{1}-t_{0}\right)\right) \\
V\left(t_{1}^{+}\right) & \leq \beta_{1} V\left(e\left(t_{1}\right)\right) \\
\text { and }: & \leq \beta_{1} V\left(e\left(t_{0}^{+}\right)\right) \exp \left(2 \lambda_{2}(A)\left(t_{1}-t_{0}\right)\right)
\end{aligned}
$$

Therefore, for $t \in\left(t_{1}, t_{2}\right]$

$$
\begin{aligned}
V(e(t)) & \leq V\left(e\left(t_{1}^{+}\right)\right) \exp \left(2 \lambda_{2}(A)\left(t-t_{1}\right)\right) \\
& \leq \beta_{1} V\left(e\left(t_{0}\right)\right) \exp \left(2 \lambda_{2}(A)\left(t-t_{0}\right)\right)
\end{aligned}
$$

In general, for $t \in\left(t_{i}, t_{i+1}\right]$

$$
V(e(t)) \leq V\left(e\left(t_{0}^{+}\right)\right) \beta_{1} \beta_{2} \ldots \beta_{i} \exp \left(2 \lambda_{2}(A)\left(t-t_{0}\right)\right)
$$

1. When $2 \lambda_{2}(A)=\lambda<0$, it follows from (12) and (20) that for $t \in$ $\left(t_{i}, t_{i+1}\right]$

$$
\begin{array}{r}
V\left(e\left(t_{0}^{+}\right)\right) \beta_{1} \beta_{2} \ldots \beta_{i} \exp \left(2 \lambda_{2}(A)\left(t-t_{0}\right)\right) \\
=V\left(e\left(t_{0}^{+}\right)\right) \beta_{1} \beta_{2} \ldots \beta_{i} \exp \left(\lambda\left(t-t_{0}\right)\right) \\
=V\left(e\left(t_{0}^{+}\right)\right) \beta_{1} \beta_{2} \ldots \beta_{i} \exp \left(-\alpha\left(t-t_{0}\right)\right) \exp \left((\alpha+\lambda)\left(t-t_{0}\right)\right)
\end{array}
$$

Then:

$$
\begin{aligned}
V(e(t)) & \leq V\left(e\left(t_{0}^{+}\right)\right) \beta_{1} \beta_{2} \ldots \beta_{i} \exp \left(-\alpha\left(t_{i}-t_{0}\right)\right) \exp \left((\alpha+\lambda)\left(t-t_{0}\right)\right) \\
& \leq V\left(e\left(t_{0}^{+}\right)\right) \exp \left((\alpha+\lambda)\left(t-t_{0}\right)\right)
\end{aligned}
$$

Which implies that the trivial solution of Eq.(9) is globally asymptotically stable. 
2. When $2 \lambda_{2}(A)=\lambda \geq 0$, it follows from (13) and (20) that for $t \in$ $\left(t_{i}, t_{i+1}\right]$

$$
\begin{aligned}
V(e(t)) \leq & V\left(e\left(t_{0}^{+}\right)\right) \beta_{1} \beta_{2} \ldots \beta_{i} \exp \left(2 \lambda_{2}(A)\left(t-t_{0}\right)\right) \\
\leq & V\left(e\left(t_{0}^{+}\right)\right) \beta_{1} \beta_{2} \ldots \beta_{i} \exp \left(\lambda\left(t_{i+1}-t_{0}\right)\right) \\
\leq & V\left(e\left(t_{0}^{+}\right)\right) \beta_{1} \exp \left(\lambda\left(t_{1}-t_{0}\right)\right) \beta_{2} \exp \left(\lambda\left(t_{3}-t_{2}\right)\right) \ldots \\
& \beta_{i} \exp \left(\lambda\left(t_{i+1}-t_{i}\right)\right) \exp \left(\lambda\left(t_{1}-t_{0}\right)\right) \\
\leq & V\left(e\left(t_{0}^{+}\right)\right) \frac{1}{\alpha^{i}} \exp \left(\lambda\left(t_{1}-t_{0}\right)\right)
\end{aligned}
$$

In practice, for the seek of convenience, the gain matrices $B_{i}$ are often selected as a constant matrix and the impulsive distances $\tau_{i}=t_{i}-t_{i-1}(i=1,2, \ldots)$ are set to be a positive constant. Then we have the following corollary.

Corollary 1. Assume $\tau_{i}=\tau>0$ and matrices $B_{i}=B,(i=1,2, \ldots)$

1. If $2 \lambda_{2}(A)=\lambda<0$ ( $\lambda$ is a constant) and there exists a constant $0 \leq$ $\alpha<-\lambda$, such that $\ln \beta_{i}-\alpha \tau \leq 0$, then the trivial solution of system (9) is globally exponentially stable.

2. If $2 \lambda_{2}(A)=\lambda \geq 0$ ( $\lambda$ is a constant) and there exists a constant $\alpha \geq 1$ , such that $\ln \left(\alpha \beta_{i}\right)+\lambda \alpha \tau \leq 0$.

\section{Numerical simulation}

In this section, numerical simulations are given to verify the proposed methods. In these numerical simulations, the fourth-order Runge-Kutta method is applied to solve the differential equations with time step size equal to 0.01 in all numerical simulations. Selected the initial values of the dynamical system $(7)$ are $x_{1}(0)=1, x_{2}(0)=1, x_{3}(0)=1, x_{4}(0)=1$ and the initial values of the response system $(8)$ are $y_{1}(0)=-1, y_{2}(0)=-5, y_{3}(0)=1, y_{4}(0)=1$, We select $\gamma=11$ and use the controller as in (18). Figures 3 and 4 shows the state time response of the dynamical system (7) and the response system (8) with the passive method for the two case. Here, the dot line stands for the track of the dynamical system and the solid line stands for the track of the response system. The error state of the dynamical system (7) and the response system (8) converges to the zero. 
For the impulsive control method, we have $A+A^{T}=\left(\begin{array}{cccc}70 & 45 & 0 & 0 \\ 45 & 20 & 0 & 0 \\ 0 & 0 & -2 & 0 \\ 0 & 0 & 0 & -20\end{array}\right)$

Its eigenvalues are $-20.00,-6.48,-2.00$ and 96.48 , then $2 \lambda_{2}(A)=\lambda=46.48>0$. If we choose the gain matrices $B_{i},(i=1,2, \ldots)$ as a constant matrix $B=$ $\operatorname{diag}\left(b_{1}, b_{2}, b_{3}\right)=(-0.30,-0.40,-0.50,-0.60)$, then it is easy to see that: $\beta=\max \left\{\left(1+b_{1}\right)^{2},\left(1+b_{2}\right)^{2},\left(1+b_{3}\right)^{2}\right\}=0.49$ Then estimates of bounds of stable regions are given by $0 \leq \tau \leq \frac{\ln \alpha+\ln (0.49)}{96.48}$. Take $\alpha=1.1$, then $0 \leq \tau \leq 0.0064$.

We choose $\tau=0.001$. Figures 5 and 6 shows the state time response of the dynamical system (7) and the response system (8) with the impulsive method for the two cases. Here, the dot line stands for the track of the dynamical system and the solid line stands for the track of the response system. The error state of the dynamical system (7) and the response system (8) converges to the zero.

\section{Conclusion}

This paper studies the synchronization problem of two identical chaotic four-Dimensional System presented by Qi et al. based on the Lyapunov stability theory and the impulsive control technology, the authors get the sufficient condition to achieve synchronization theoretically by passive control method and passive control method. An illustrative simulation is finally included to visualize the effectiveness and feasibility of the developed methods. 

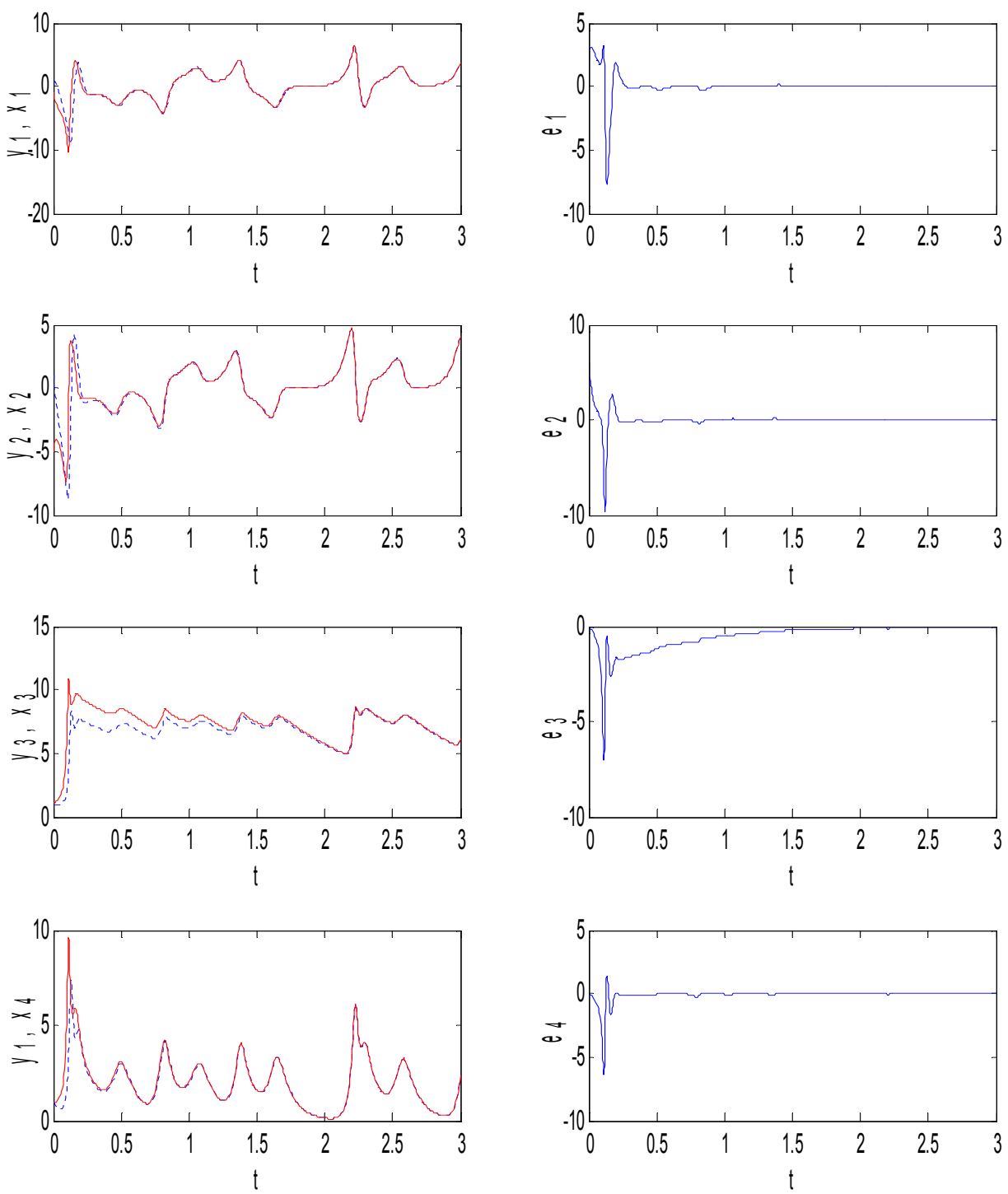

Figure 3: Synchronization of $4 D$ chaotic system with passive control method for case I 

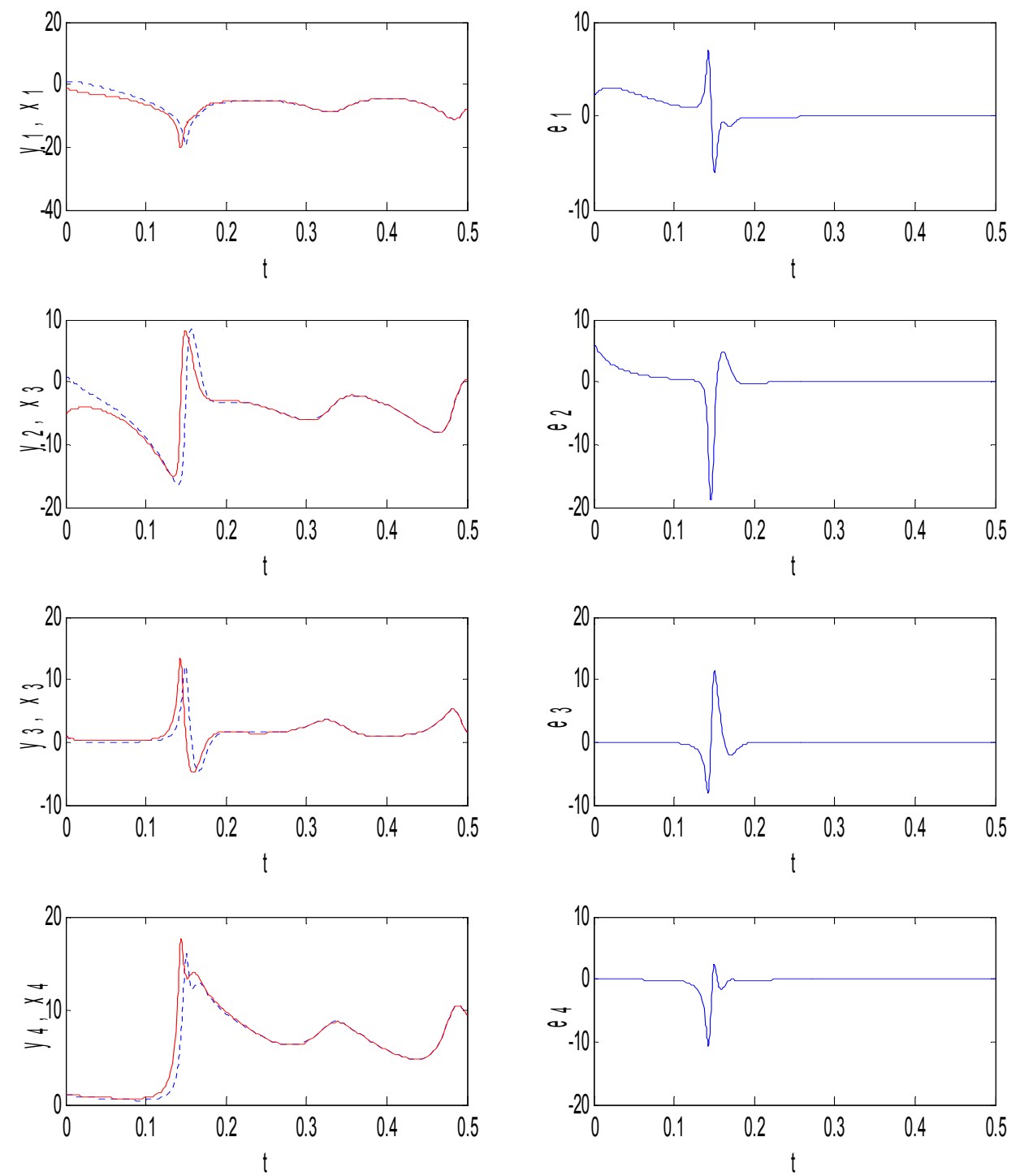

Figure 4: Synchronization of $4 D$ chaotic system with passive control method for case II 

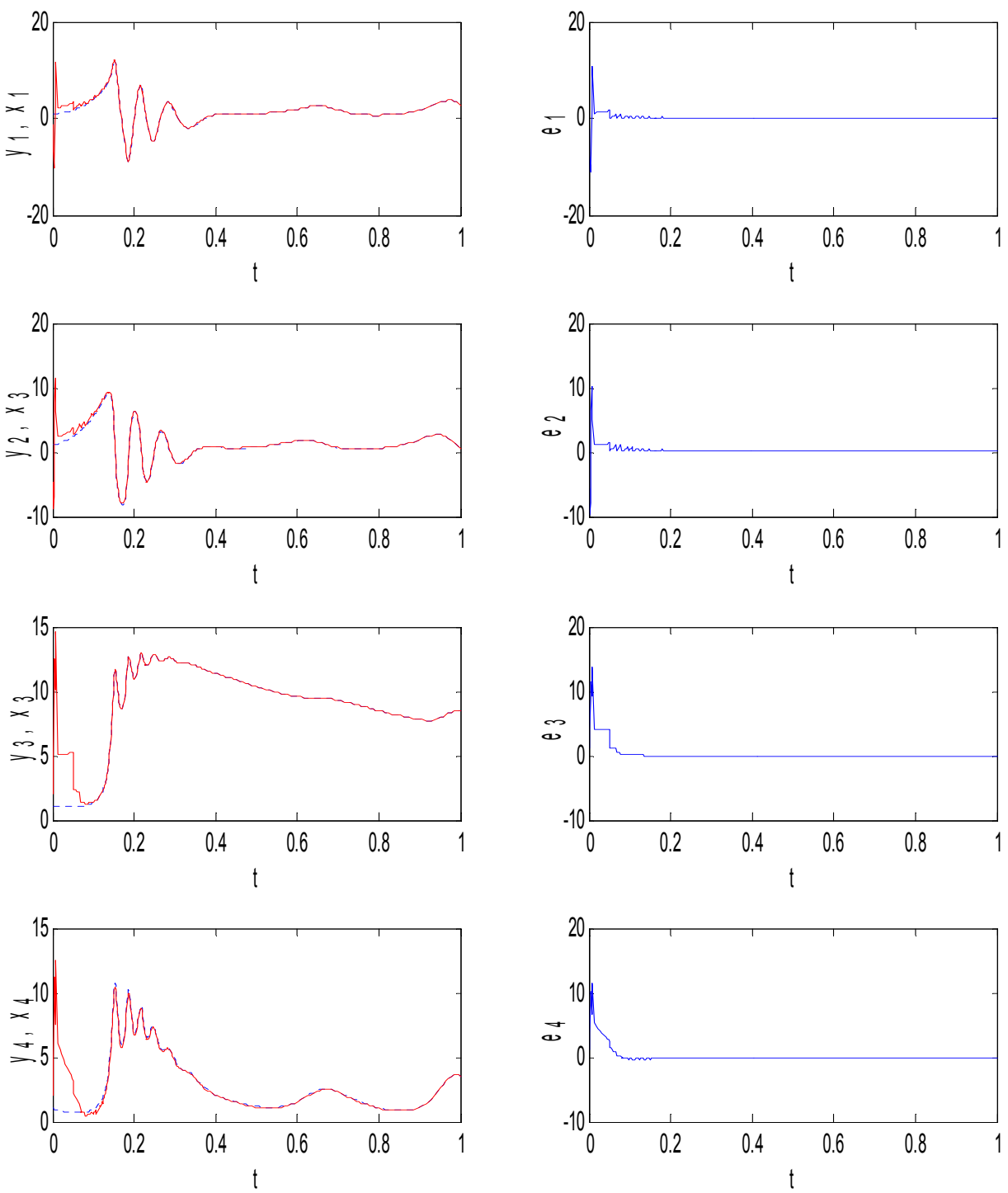

Figure 5: Synchronization of $4 D$ chaotic system with impulsive control method for case I 

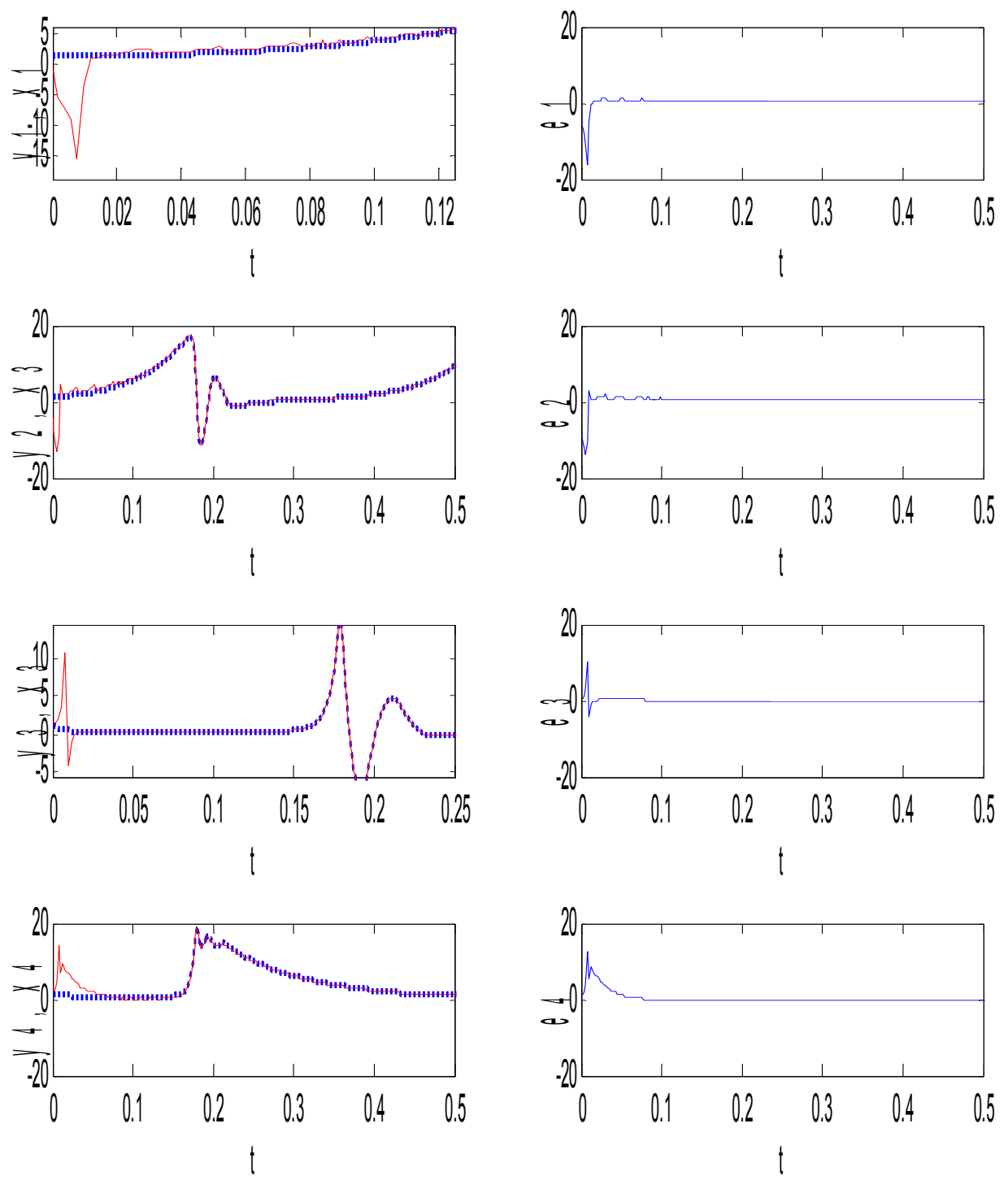

Figure 6: Synchronization of $4 D$ chaotic system with impulsive control method for case II 


\section{References}

C. Sparrow, The lorenz equation: bifurcations, chaos and strange attractors, NY: Springer-Verlag, 1982.

OE. Rössler, An equation for continuous chaos, Physics Letters A, vol. 57, no. 5, pp. 397-398, 1976.

G. Chen and T. Ueta, Yet another chaotic attractor, International Journal of Bifurcation and Chaos, vol. 9, no. 7, pp. 1465-1466, 1999.

J. Lü and G. Chen, A new chaotic attractor coined, International Journal of Bifurcation and Chaos, vol. 12, no.3, pp. 659-661, 2002.

J. Lü, G. Chen, D. Cheng and S. Celikovsky, Bridge the gap between the lorenz system and the chen system, International Journal of Bifurcation and Chaos, vol. 12, no.12, pp. 2917-2926, 2003.

W. Wu, Z. Chen and Z. Yuan, The evolution of a nouvel four-dimensional autonomous system: Among 3-torus, limit cycle, 2-torus, chaos and hyperchaos, Chaos, Solitons and Fractals, 2007.

J. Sun, Impulsive control of a new chaotic system, Mathematics and Computers in Simulation, vol. 64, pp. 669-677, 2004.

G. Qi, S. Du, G. Chen, Z. Chen and Z. Yuan, On a four-dimensional chaotic system, Chaos, Solitons and Fractals, Vol. 23, pp. 1671-1682, 2005.

G. Qi , G. Chen, Analysis and circuit implementation of a new 4D chaotic system, Physics Letters A, vol. 352, no.4-5, pp. 386-397, 2006.

U.E. Vincent, Synchronization of identical and non-identical 4-D chaotic systems using active control, Chaos, Solitons and Fractals, vol. 37,no.4, pp. 1065-1075, 2008.

Y. C. Lai and C. Grebogi, Synchronization of chaotic trajectories using active control, Physical Review E, vol. 47, no.4, pp. 2357-2359, 1993.

X. Han , J.A. Lu and X. Wu, Adaptive feedback synchronization of Lü system, Chaos, Solitons and Fractals, vol. 22, no.1, pp. 221-227, 2004. 
T. L. Liao, Adaptive synchronization of two Lorenz systems. Chaos, Solitons and Fractals, vol. 9, no.9, pp. 1555-1561, 1998.

X.H. Tan, J.Y. Zhang and Y.R. Yang, Synchronization chaotic systems using backstepping design, Chaos, Solitons and Fractals, vol. 16, no.1, pp. 37-45, 2003.

Y. Shimizu, M. Miyazaki, H.H. Lee et al, Chaos synchronization based on fuzzy model using sliding mode control, International Journal of Innovative Computing Information and Control, vol. 1, no.3, pp.563-579, 2005.

L. Liu, J; Lu, JN; Shi, Y, et al, Different type of synchronization phenomena in unidirectional coupled unified chaotic systems, International Journal of Innovative Computing Information and Control, vol. 3, no.3, pp.697-708, 2007.

W. Yu, Passive equivalence of chaos in Lorenz system, IEEE Transaction on Circuits and Systems-1:Fundamental Theory and Applications, vol.46, no.7, pp.876-878, 1999.

K. Kemih et al., Passivity-based control of chaotic L system, International Journal of Innovative Computing, Information and Control, vol. 2, no.2, pp.331-337, 2006.

K. Kemih et al., Synchronization of Chen System Based on Passivity Technique for CDMA Underwater Communication, International Journal of Innovative Computing, Information And Control, vol. 3, no.5, pp. 13011308, 2007.

Q. Zhang, J. Lu., Impulsive Control and Synchronization, of a Critical Chaotic System, Wuhan University Journal of Natural Sciences, vol.12, no.3, pp. 426-430, 2007. 